\title{
Mapping Research Trends of Universal Health Coverage From 1990 to 2019: Bibliometric Analysis
}

Mahboubeh Khaton Ghanbari ${ }^{1}, \mathrm{PhD}$; Masoud Behzadifar ${ }^{2}, \mathrm{PhD}$; Leila Doshmangir ${ }^{3}, \mathrm{PhD}$; Mariano Martini ${ }^{4}, \mathrm{PhD}$; Ahad Bakhtiari ${ }^{5}$, PhD; Mahtab Alikhani ${ }^{6}$, PhD; Nicola Luigi Bragazzi ${ }^{4}, \mathrm{MPH}, \mathrm{MD}, \mathrm{PhD}$

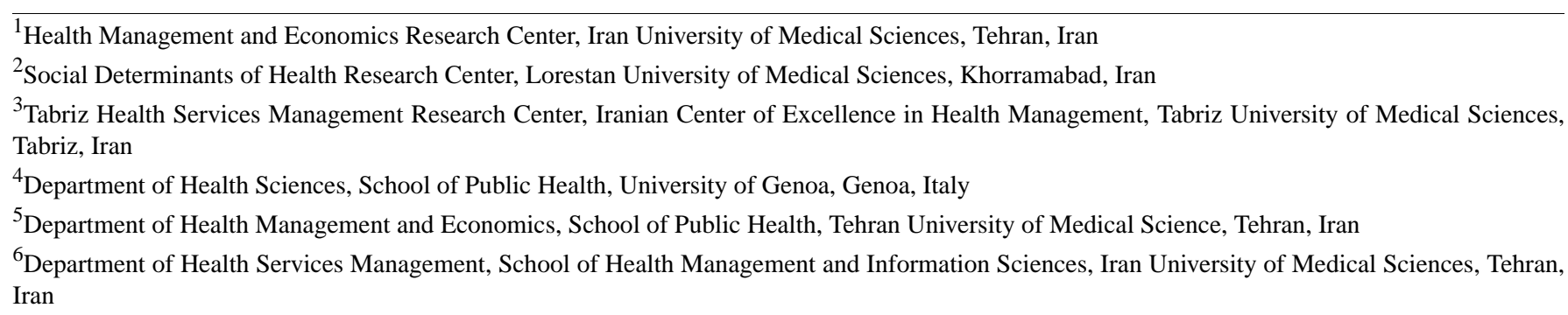

Corresponding Author:

Masoud Behzadifar, $\mathrm{PhD}$

Social Determinants of Health Research Center

Lorestan University of Medical Sciences

Anooshirvan Rezaei Square

Khorramabad, 6813833946

Iran

Phone: 989128934237

Email: masoudbehzadifar@gmail.com

\section{Abstract}

Background: Universal health coverage (UHC) is one of many ambitious, health-related, sustainable development goals. Sharing various experiences of achieving UHC, in terms of challenges, pitfalls, and future prospects, can help policy and decision-makers reduce the likelihood of committing errors. As such, scholarly articles and technical reports are of paramount importance in shedding light on the determinants that make it possible to achieve UHC.

Objective: The purpose of this study is to conduct a comprehensive analysis of UHC-related scientific literature from 1990 to 2019.

Methods: We carried out a bibliometric analysis of papers related to UHC published from January 1990 to September 2019 and indexed in Scopus via VOSviewer (version 1.6.13; CWTS). Relevant information was extracted: the number of papers published, the 20 authors with the highest number of publications in the field of UHC, the 20 journals with the highest number of publications related to UHC, the 20 most active funding sources for UHC-related research, the 20 institutes and research centers that have produced the highest number of UHC-related research papers, the 20 countries that contributed the most to the research field of UHC, the 20 most cited papers, and the latest available impact factors of journals in 2018 that included the UHC-related items under investigation.

Results: In our analysis, 7224 articles were included. The publication trend was increasing, showing high interest in the scientific community. Most researchers were from the United States, the United Kingdom, and Canada, with Thailand being a notable exception. The Lancet accounted for 3.95\% of published UHC-related research. Among the top 20 funding sources, the World Health Organization (WHO), the Bill and Melinda Gates Foundation, and the National Institutes of Health (NIH) accounted for $1.41 \%, 1.34 \%$, and $1.02 \%$ of published UHC-related research, respectively. The highest number of citations was found for articles published in The Lancet, the American Journal of Psychiatry, and the Journal of the American Medical Association (JAMA). The top keywords were "health insurance," "insurance," "healthcare policy," "healthcare delivery," "economics," "priority," "healthcare cost," "organization and management," "health services accessibility," "reform," "public health," and "health policy."

Conclusions: The findings of our study showed an increasing scholarly interest in UHC and related issues. However, most research concentrated in middle- and high-income regions and countries. Therefore, research in low-income countries should be 
promoted and supported, as this could enable a better understanding of the determinants of the barriers and obstacles to UHC achievement and improve global health.

(JMIR Public Health Surveill 2021;7(1):e24569) doi: 10.2196/24569

\section{KEYWORDS}

bibliometrics; scientometrics; universal health coverage; universal health; health coverage; developing countries; low-income countries

\section{Introduction}

Universal health coverage (UHC) was one of the ambitious, health-related "sustainable development goals" (SDGs) set by the United Nations (UN) General Assembly in 2015, and is one of the top priorities of their 2030 agenda. UHC represents the hope for better health for the world's poorest [1-3]. The World Health Organization (WHO) has defined UHC as a policy for "ensuring that all people can use the promotive, preventive, curative, rehabilitative and palliative health services they need, of sufficient quality to be effective, while also ensuring that the use of these services does not expose the user to financial hardship" [4].

At least half of the world's population does not have access to full coverage for a package of essential health services [5]. Health expenses lead more than 100 million people worldwide to extreme poverty every year, often forcing people to make intolerably difficult choices between purchasing food for their children and families, paying for child education, or paying for vital health services $[2,6]$.

Countries differ in the way they address UHC provision based on a wide range of factors, such as political, economic, social, epidemiological, and technical considerations [7,8]. The path to UHC involves important policy choices and inevitable trade-offs [9]. The extent of the impact of a successful UHC implementation is referred to as the "Third Global Health Transition" [10]. Sharing various experiences of achieving UHC, in terms of challenges, pitfalls, and future prospects, can help policy and decision-makers benefit from global good practices and reduce the likelihood of committing errors and wasting resources better allocated elsewhere. As such, scholarly articles and technical reports are of paramount importance in shedding light on the determinants that make UHC achievement possible $[11,12]$.

Nearly all of the Organization for Economic Co-operation and Development (OECD) countries and emerging economies, such as Brazil, China, Colombia, Costa Rica, India, Indonesia, and Russia, have achieved UHC [13]. These countries' experiences can be a major source of evidence of why UHC is desirable and how it should be achieved. Evidence shows a strong relationship between life expectancy at birth and UHC indicators, reflecting the 3 core dimensions of universal health coverage [14]. In moving to UHC, some countries such as Ghana, Indonesia, and Vietnam have increased their UHC indices over time, $1.43 \%$, $1.85 \%$, and $2.26 \%$, respectively, mostly by improving both financial protection and service coverage $[15,16]$.

In recent years, researchers have been using scientometrics, a branch of information science and a subfield of bibliometrics, to quantitatively investigate emerging research patterns in the scientific literature [17]. In addition, scientometrics enables an assessment of trends in article citations and how these indicators and measurements can impact policy and management. Using scholarly databases and visualization technology allows researchers to gain a good understanding of the publication trends related to a given topic $[18,19]$.

To the best of our knowledge, there is a dearth of information concerning research patterns in the field of health care management and, specifically, UHC. Therefore, the purpose of this study is to conduct a comprehensive analysis of UHC-related scientific literature from 1990 to 2019.

\section{Methods}

\section{Ethics Approval and Consent to Participate}

This study was waived from ethical approval because it did not include data on animals or human subjects, and it was based on publicly available data.

\section{Data Sources}

This quantitative study was based on medical informatics, data and text mining, and scientometrics techniques [20]. Independently, 2 authors searched Scopus from January 1, 1990, to September 24, 2019. Disagreements between them were resolved through discussion until consensus was reached.

\section{Inclusion and Exclusion Criteria}

We limited our search to only scholarly items dealing with UHC, using "universal health coverage" as the keyword. The search was performed without language restrictions. All records relevant to the field of UHC were deemed eligible and, as such, retained in our investigation.

\section{Data Extraction}

Data were downloaded in comma-separated values (CSV) format. Independently, 2 authors extracted relevant data, namely, (1) the number of documents published within the study period, (2) the 20 authors with the highest number of publications in the field of UHC, (3) the 20 journals with the highest number of publications related to UHC, (4) the 20 most active funding sources for UHC-related research, (5) the 20 institutes and research centers that have produced the highest number of UHC-related research papers, (6) the 20 countries that contributed the most to the research field of UHC, (7) the 20 most highly cited papers, and (8) the latest available impact factor of journals in 2018 that included the UHC-related items under investigation. Any disagreements between the 2 authors were resolved through discussion until consensus was reached. 


\section{Data Analysis}

Ad hoc visualization software was used to visualize UHC-related research hotspots, patterns, directions of research development, and other relevant trends, using networks and graphs. All data were imported and loaded into VOSviewer (version 1.6.13; CWTS). For visualization publication density worldwide (ie, publication trends among countries), the open-source tool GunnMap was used [21].

\section{Results}

After searching Scopus, a pool of 7224 records was included in our analysis. The increasing publication trend related to UHC from January 1990 to September 2019 is shown in Table 1.
The 20 authors with the highest number of publications in the field of UHC are listed in Table 2. Of the 20 authors, 4 are from the United States, 4 are from the United Kingdom, and 3 are from Thailand.

The network distribution of authors publishing in the field of UHC is shown in Figure 1. The 20 journals with the highest number of publications related to UHC are listed in Table 3. The Lancet accounted for $3.95 \%$ of published UHC-related research.

Table 1. Number of publications related to universal health coverage per year, as indexed in Scopus.

\begin{tabular}{|c|c|}
\hline Year & Number of publications \\
\hline 1990 & 25 \\
\hline 1991 & 21 \\
\hline 1992 & 38 \\
\hline 1993 & 50 \\
\hline 1994 & 103 \\
\hline 1995 & 70 \\
\hline 1996 & 53 \\
\hline 1997 & 70 \\
\hline 1998 & 77 \\
\hline 1999 & 73 \\
\hline 2000 & 115 \\
\hline 2001 & 83 \\
\hline 2002 & 87 \\
\hline 2003 & 138 \\
\hline 2004 & 129 \\
\hline 2005 & 136 \\
\hline 2006 & 188 \\
\hline 2007 & 266 \\
\hline 2008 & 254 \\
\hline 2009 & 308 \\
\hline 2010 & 251 \\
\hline 2011 & 312 \\
\hline 2012 & 393 \\
\hline 2013 & 398 \\
\hline 2014 & 449 \\
\hline 2015 & 581 \\
\hline 2016 & 628 \\
\hline 2017 & 668 \\
\hline 2018 & 784 \\
\hline 2019 & 525 \\
\hline
\end{tabular}


Table 2. Authors with the highest number of manuscripts related to universal health coverage.

\begin{tabular}{|c|c|c|c|c|c|c|}
\hline Rank & Author's name & Country & Number of publications & Citations & Percentage (n/7224) & H-index \\
\hline 1 & Tangcharoensathien $\mathrm{V}$ & Thailand & 47 & 3117 & 0.64 & 29 \\
\hline 2 & Atun R & United States & 35 & 9121 & 0.48 & 48 \\
\hline 3 & Teerawattananon Y & Singapore & 31 & 3865 & 0.42 & 27 \\
\hline 4 & Chalkidou K & United Kingdom & 23 & 2223 & 0.31 & 22 \\
\hline 5 & McIntyre D & South Africa & 23 & 2197 & 0.31 & 27 \\
\hline 6 & Norheim OF & Norway & 23 & 19675 & 0.31 & 42 \\
\hline 7 & Ridde V & Canada & 23 & 2455 & 0.31 & 24 \\
\hline 8 & Hanson $\mathrm{K}$ & United Kingdom & 21 & 5268 & 0.28 & 39 \\
\hline 9 & McKee M & United Kingdom & 21 & 51327 & 0.28 & 96 \\
\hline 10 & Mills A & United Kingdom & 21 & 9487 & 0.28 & 56 \\
\hline 11 & Ataguba JE & South Africa & 20 & 893 & 0.27 & 15 \\
\hline 12 & Shibuya K & Japan & 20 & 58828 & 0.27 & 66 \\
\hline 13 & Bello AK & Canada & 19 & 7133 & 0.26 & 32 \\
\hline 14 & Kruk ME & United States & 19 & 4671 & 0.26 & 38 \\
\hline 15 & Woolhandler S & United States & 19 & 10241 & 0.26 & 47 \\
\hline 16 & Limwattananon S & Thailand & 18 & 10241 & 0.24 & 47 \\
\hline 17 & Patcharanarumol W & Thailand & 18 & 714 & 0.24 & 12 \\
\hline 18 & Prinja S & India & 18 & 1087 & 0.24 & 19 \\
\hline 19 & Reich MR & United States & 18 & 3580 & 0.24 & 32 \\
\hline 20 & Bhutta ZA & Pakistan & 17 & 69758 & 0.23 & 114 \\
\hline
\end{tabular}

Figure 1. The distribution of authors publishing research in the field of universal health coverage.

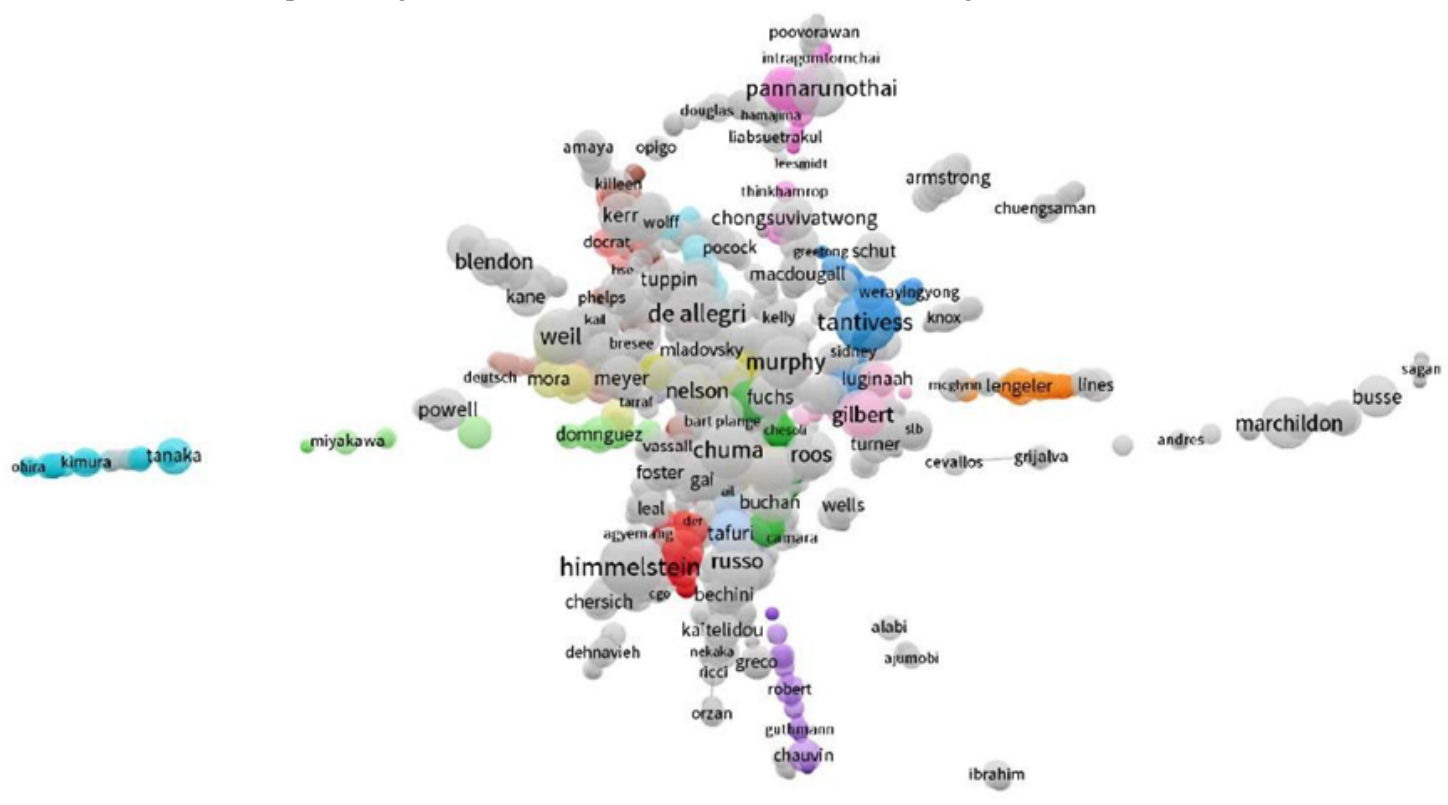


Table 3. Journals with the highest number of articles related to universal health coverage.

\begin{tabular}{|c|c|c|c|c|c|c|}
\hline Rank & Journal & $\begin{array}{l}\text { Number of } \\
\text { publications }\end{array}$ & $\begin{array}{l}\text { Percentage } \\
(\mathrm{n} / 7224)\end{array}$ & $\begin{array}{l}\text { Impact } \\
\text { factor (2018) }\end{array}$ & $\begin{array}{l}\text { Quartile in category } \\
(2018)\end{array}$ & H-index \\
\hline 1 & Lancet & 286 & 3.95 & 59.102 & Q1 & 700 \\
\hline 2 & Health Affairs & 152 & 2.09 & 5.711 & Q1 & 156 \\
\hline 3 & Plos One & 152 & 2.09 & 2.776 & Q1 & 268 \\
\hline 4 & BMC Health Services Research & 131 & 1.8 & 1.932 & Q1 & 90 \\
\hline 5 & Bulletin of The World Health Organization & 124 & 1.71 & 6.818 & Q1 & 148 \\
\hline 6 & Modern Healthcare & 120 & 1.65 & $-^{\mathrm{a}}$ & Q4 & 9 \\
\hline 7 & International Journal for Equity in Health & 115 & 1.58 & 2.473 & Q1 & 46 \\
\hline 8 & Health Policy and Planning & 105 & 1.44 & 2.717 & Q1 & 80 \\
\hline 9 & Health Policy & 95 & 1.31 & 2.075 & Q1 & 79 \\
\hline 10 & Social Science and Medicine & 93 & 1.28 & 3.087 & Q1 & 213 \\
\hline 11 & BMC Public Health & 82 & 1.13 & 2.567 & Q1 & 117 \\
\hline 12 & Vaccine & 81 & 1.11 & 4.760 & Q1 & 164 \\
\hline 13 & Malaria Journal & 77 & 1.06 & 2.798 & Q1 & 87 \\
\hline 14 & New England Journal of Medicine & 75 & 1.03 & 70.670 & Q1 & 933 \\
\hline 15 & BMJ Global Health & 63 & 0.86 & 4.28 & Q1 & 21 \\
\hline 16 & Journal of Health Politics Policy and Law & 54 & 0.74 & 1.839 & Q2 & 48 \\
\hline 17 & American Journal of Public Health & 52 & 0.71 & 0.774 & Q1 & 236 \\
\hline 18 & Health Systems and Reform & 51 & 0.7 & - & - & - \\
\hline 19 & International Journal of Health Planning and Management & 50 & 0.68 & 1.450 & Q2 & 37 \\
\hline 20 & Global Health Action & 50 & 0.68 & 1.817 & Q1 & 33 \\
\hline
\end{tabular}

a _not available.

Table 4 shows the 20 most active funding sources for UHC-related research. Among them, the WHO, the Bill and Melinda Gates Foundation, and the National Institutes of Health (NIH) accounted for $1.41 \%, 1.34 \%$, and $1.02 \%$ of published UHC-related research, respectively.

Table 5 lists the 20 institutes and research centers that have produced the highest number of UHC-related research papers.

Table 6 shows the countries that contributed the most to the research field of UHC. Among them, the United States, the United Kingdom, and Canada contributed 2426, 919, and 545 papers, respectively.
Figure 2 shows the density distribution of UHC-related publications among different countries and regions around the world.

The 20 most highly cited papers are listed in Table 7. The highest number of citations was found for papers published in The Lancet, the American Journal of Psychiatry, and the Journal of the American Medical Association (JAMA).

In Figure 3, the network of words, themes, and topics associated with UHC is shown. Among them, the top keywords were "health insurance," "insurance," "healthcare policy," "healthcare delivery," "economics," "priority," "healthcare cost," "organization and management," "health services accessibility," "reform," "public health," and "health policy." 
Table 4. Most active funding sources for universal health coverage (UHC)-related research.

\begin{tabular}{|c|c|c|}
\hline Rank & Name of Institute & Number of publications \\
\hline 1 & World Health Organization & 102 \\
\hline 2 & London School of Hygiene \& Tropical Medicine & 97 \\
\hline 3 & Harvard School of Public Health & 74 \\
\hline 4 & University of Toronto & 65 \\
\hline 5 & Harvard Medical School & 47 \\
\hline 6 & University of Cape Town & 45 \\
\hline 7 & Johns Hopkins Bloomberg School of Public Health & 39 \\
\hline 8 & Imperial College London & 34 \\
\hline 9 & Centers for Disease Control and Prevention & 33 \\
\hline 10 & Thailand Ministry of Public Health & 30 \\
\hline 11 & University of California, San Francisco & 26 \\
\hline 12 & Johns Hopkins University & 24 \\
\hline 13 & University of Oxford & 22 \\
\hline 14 & University of Washington, Seattle & 22 \\
\hline 15 & University of Witwatersrand & 21 \\
\hline 16 & Harvard University & 21 \\
\hline 17 & Columbia University in the City of New York & 20 \\
\hline 18 & The World Bank & 19 \\
\hline 19 & UCL & 18 \\
\hline 20 & University of Melbourne & 17 \\
\hline
\end{tabular}


Table 5. Highest producing institutes and research centers for universal health coverage research.

\begin{tabular}{|c|c|c|}
\hline Institute & Number of publications & Percentage of total \\
\hline Organisation Mondiale de la Santé & 388 & 5.35 \\
\hline London School of Hygiene \& Tropical Medicine & 269 & 3.71 \\
\hline Harvard School of Public Health & 194 & 2.67 \\
\hline University of Toronto & 164 & 2.26 \\
\hline Harvard Medical School & 147 & 2.02 \\
\hline University of Cape Town & 112 & 1.54 \\
\hline Johns Hopkins Bloomberg School of Public Health & 104 & 1.43 \\
\hline Imperial College London & 104 & 1.43 \\
\hline Centers for Disease Control and Prevention & 102 & 1.4 \\
\hline Thailand Ministry of Public Health & 98 & 1.35 \\
\hline University of California, San Francisco & 93 & 1.28 \\
\hline Johns Hopkins University & 89 & 1.22 \\
\hline University of Oxford & 87 & 1.2 \\
\hline University of Washington, Seattle & 86 & 1.18 \\
\hline University of Witwatersrand & 79 & 1.09 \\
\hline Harvard University & 78 & 1.07 \\
\hline Columbia University in the City of New York & 75 & 1.03 \\
\hline The World Bank, USA & 73 & 1 \\
\hline UCL & 69 & 0.95 \\
\hline University of Melbourne & 68 & 0.93 \\
\hline
\end{tabular}


Table 6. Countries and regions that contributed the most to the research field of universal health coverage (UHC) during 1990-2019.

\begin{tabular}{|c|c|}
\hline Country & Number of UHC-related research papers contributed \\
\hline United States & 2426 \\
\hline United Kingdom & 919 \\
\hline Canada & 545 \\
\hline Switzerland & 469 \\
\hline India & 395 \\
\hline Australia & 370 \\
\hline South Africa & 299 \\
\hline Thailand & 285 \\
\hline Brazil & 219 \\
\hline China & 215 \\
\hline France & 205 \\
\hline Japan & 181 \\
\hline Italy & 176 \\
\hline Netherlands & 173 \\
\hline Germany & 161 \\
\hline Spain & 158 \\
\hline Belgium & 149 \\
\hline Mexico & 131 \\
\hline Taiwan & 129 \\
\hline Kenya & 120 \\
\hline
\end{tabular}

Figure 2. Density of publications related to the research field of universal health coverage worldwide.

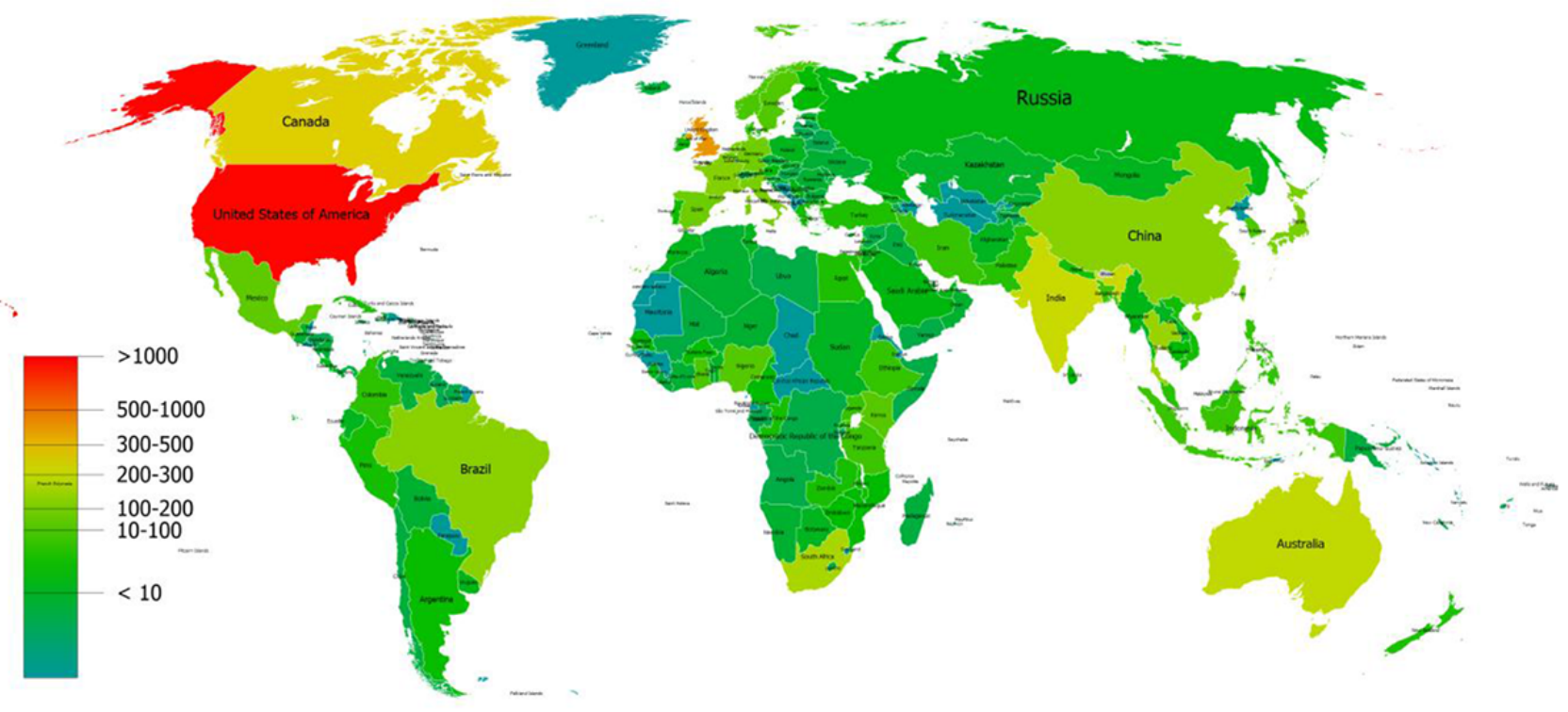


Table 7. Most cited papers related to universal health coverage.

\begin{tabular}{|c|c|c|c|c|}
\hline No. & Title & Year & Journal & $\begin{array}{l}\text { Number of } \\
\text { citations }\end{array}$ \\
\hline 1 & Evidence-based, cost-effective interventions: How many newborn babies can we save? & 2005 & Lancet & 933 \\
\hline 2 & Social consequences of psychiatric disorders, I: Educational attainment & 1995 & $\begin{array}{l}\text { American Journal of Psy- } \\
\text { chiatry }\end{array}$ & 729 \\
\hline 3 & $\begin{array}{l}\text { Global Surgery 2030: Evidence and solutions for achieving health, welfare, and eco- } \\
\text { nomic development }\end{array}$ & 2015 & Lancet & 716 \\
\hline 4 & Socioeconomic Inequalities in Health: No Easy Solution & 1993 & JAMA & 696 \\
\hline 5 & Hepatitis B virus infection: Epidemiology and vaccination & 2006 & Epidemiologic Reviews & 615 \\
\hline 6 & Persistence of use of lipid-lowering medications: A cross-national study & 1998 & $\begin{array}{l}\text { Journal of the American } \\
\text { Medical Association }\end{array}$ & 550 \\
\hline 7 & Early appraisal of China's huge and complex health-care reforms & 2012 & Lancet & 541 \\
\hline 8 & Applying an equity lens to child health and mortality: More of the same is not enough & 2003 & Lancet & 485 \\
\hline 9 & Taiwan's new national health insurance program: Genesis and experience so far & 2003 & Health Affairs & 458 \\
\hline 10 & $\begin{array}{l}\text { Varicella disease after introduction of varicella vaccine in the United States, 1995- } \\
2000\end{array}$ & 2002 & $\begin{array}{l}\text { Journal of the American } \\
\text { Medical Association }\end{array}$ & 427 \\
\hline 11 & Does universal health insurance make health care unaffordable? Lessons from Taiwan & 2003 & Health Affairs & 406 \\
\hline 12 & Maternal and child health in Brazil: Progress and challenges & 2011 & Lancet & 402 \\
\hline 13 & $\begin{array}{l}\text { Establishment of a universal size standard strain for use with the pulsenet standardized } \\
\text { pulsed-field gel electrophoresis protocols: Converting the national databases to the } \\
\text { new size standard }\end{array}$ & 2005 & $\begin{array}{l}\text { Journal of Clinical Micro- } \\
\text { biology }\end{array}$ & 400 \\
\hline 14 & Help-seeking and access to mental health care in a university student population & 2007 & Medical Care & 369 \\
\hline 15 & $\begin{array}{l}\text { Policy statement: Recommendations for the prevention of pneumococcal infections, } \\
\text { including the use of pneumococcal conjugate vaccine (Prevnar), pneumococcal } \\
\text { polysaccharide vaccine, and antibiotic prophylaxis }\end{array}$ & 2008 & Pediatrics & 348 \\
\hline 16 & Explaining income-related inequalities in doctor utilisation in Europe & 2004 & Health Economics & 345 \\
\hline 17 & $\begin{array}{l}\text { Access to care, health status, and health disparities in the United States and Canada: } \\
\text { Results of a Cross-National Population-Based Survey }\end{array}$ & 2006 & $\begin{array}{l}\text { American Journal of Pub- } \\
\text { lic Health }\end{array}$ & 325 \\
\hline 18 & The history and principles of managed competition & 1993 & Health Affairs & 317 \\
\hline 19 & $\begin{array}{l}\text { Socioeconomic Disparities in Preventive Care Persist Despite Universal Coverage: } \\
\text { Breast and Cervical Cancer Screening in Ontario and the United States }\end{array}$ & 1994 & JAMA & 310 \\
\hline 20 & Policy relevant determinants of health: An international perspective & 2002 & Health Policy & 307 \\
\hline
\end{tabular}


Figure 3. Network of the most used keywords related to universal health coverage.

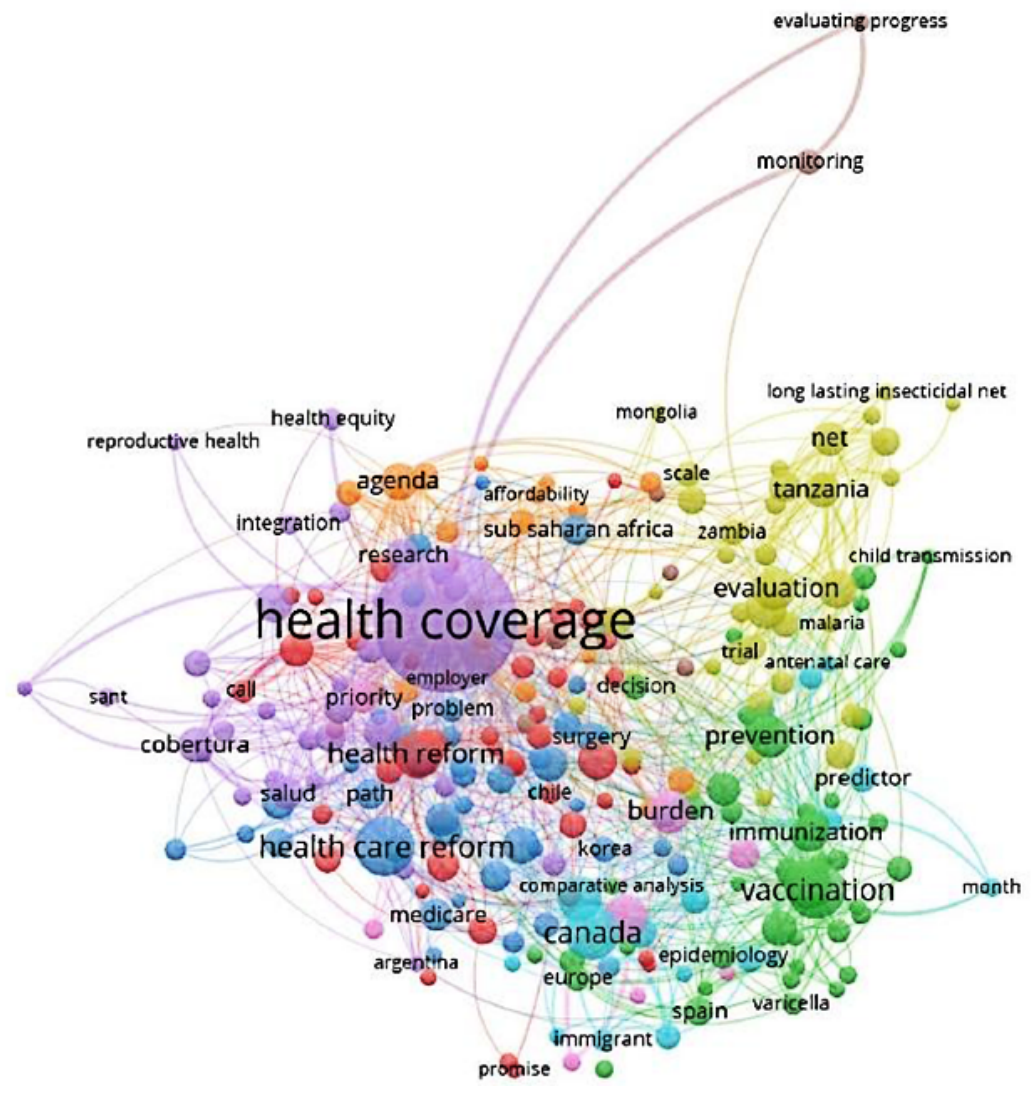

\section{Discussion}

\section{Principal Findings}

This study quantitatively assessed the publication trend related to UHC over the past 19 years. UHC-related publications have been on the rise in recent years, and this seems to be the major focus of researchers, given the important role that UHC can play in improving equity in access to health services and provisions. UHC can enable important achievements in the health sector worldwide. The growth of health-related scientific publications in the field of policy and management, and especially UHC, reflects the global interest and participation of different stakeholders, including researchers, in identifying the different dimensions and determinants that can make it possible to achieve UHC.

Undoubtedly, relying on scholarly publications can improve the performance of the health sector to achieve UHC-related goals. The rigor of the scientific method, if properly followed, can lead to fundamental changes in all areas of life, including health. Bibliometrics-based literature reviews can play an important role in examining the process of scientific publications and orienting researchers in this field [22].

From 1990 to 2019, scholarly publications in the field of UHC have been gradually increasing, especially after 2015 when policy and decision-makers have given particular emphasis to achieving UHC as one of the SDGs. Political commitment and support on this issue has contributed to the prioritization of $\mathrm{UHC}$ and put it on the policy and research agenda [23].
This investigation shows that authors from the United States, the United Kingdom, Canada, and Thailand produced the highest number of publications related to UHC. Scientists from the United States, the United Kingdom, and Canada have done research on the possible ways to achieve UHC goals in collaboration with various stakeholders, including health care policy and decision-makers. Thailand is one of the countries working hard to improve its health sector by making profound reforms. Since 2002, despite economic-financial problems and political instability, proper support for UHC has provided Thai citizens with a good level of health services and provisions. Therefore, researchers in this country have tried to disseminate their experiences and practices in the field of UHC to other countries around the world [24].

Usually, researchers aim to have their scientific findings published in prestigious journals so that their papers can have the highest exposure in terms of impact and receive adequate attention and citations from other researchers [25]. The Lancet, which has a high impact factor and plays an important role in influencing and shaping future scientific research, has published the highest number of articles related to UHC. Also, journals in the fields of health care policymaking, decision-making, and management have attracted authors' interest in submitting papers. UHC is a major topic because of its impact on all aspects of health [26].

The WHO, the London School of Hygiene and Tropical Medicine, and the Harvard School of Public Health were among the institutions and research centers that played a major role in supporting UHC-related research. The WHO's institutional nature makes it naturally interested in topics such as UHC, as 
it strives to provide the best evidence for a given health-related issue. The London School of Hygiene and Tropical Medicine is also one of the most prestigious institutions that, in recent decades, has promoted UHC-related studies, especially in lower-income countries, to improve health in these countries and achieve UHC goals. It strives to empower researchers in the field of health and provide high-quality public health education, as does Harvard School of Public Health.

It is important to note that, in the last decades, these two institutions have become prominent in the fields of health policy and management, indicating that they play an important role in developing UHC-related issues.

\section{Limitations}

Despite strengths such as methodological rigor, transparency, and reproducibility, this study has some limitations that should be properly recognized. Its major limitation is the use of a single bibliographic database (Scopus). As such, results should be replicated utilizing other major scholarly databases like PubMed/MEDLINE or Web of Science.

\section{Conclusion}

The findings of our study showed an increasing scholarly interest in UHC and related issues. However, most researchers were from the United States, the United Kingdom, and Canada, with Thailand being a notable exception. Research in low-income countries should be promoted and supported, as this could enable a better understanding of the determinants of the barriers and obstacles to UHC achievement and improve global health.

\section{Authors' Contributions}

MB, LD, and NLB conceived of the premise for this paper. MB, MM, AB, and MKG designed the research. MB, LD, AB, NLB, and MA conceived of the methodology. MB, LD, NLB, and AB performed the data analysis, graphics, and data interpretation. $\mathrm{MB}, \mathrm{LD}, \mathrm{MM}, \mathrm{AB}, \mathrm{MKG}$, and NLB wrote and submitted the manuscript.

\section{Conflicts of Interest}

None declared.

\section{References}

1. Kruk ME, Gage AD, Joseph NT, Danaei G, García-Saisó S, Salomon JA. Mortality due to low-quality health systems in the universal health coverage era: a systematic analysis of amenable deaths in 137 countries. The Lancet 2018 Nov;392(10160):2203-2212. [doi: 10.1016/s0140-6736(18)31668-4]

2. Evans DB, Hsu J, Boerma T. Universal health coverage and universal access. Bull. World Health Organ 2013 Aug 01;91(8):546-546A. [doi: 10.2471/blt.13.125450]

3. Hogan DR, Stevens GA, Hosseinpoor AR, Boerma T. Monitoring universal health coverage within the Sustainable Development Goals: development and baseline data for an index of essential health services. The Lancet Global Health 2018 Feb;6(2):e152-e168. [doi: 10.1016/s2214-109x(17)30472-2]

4. Pandey KR. From health for all to universal health coverage: Alma Ata is still relevant. Global Health 2018 Jul 3;14(1):62. [doi: 10.1186/s12992-018-0381-6]

5. Giovanella L, Mendoza-Ruiz A, Pilar A, Rosa M, Martins G, Santos I. Universal health system and universal health coverage: assumptions and strategie. Cien Saude Colet 2018;23(6):1763-1776. [doi: 10.1093/oso/9780190662455.003.0011]

6. Garg S. Universal health coverage in India: Newer innovations and the role of public health. Indian J Public Health 2018;62(3):167-170. [doi: 10.4103/ijph.ijph 221 18]

7. Gupta V, Kerry VB, Goosby E, Yates R. Politics and Universal Health Coverage — The Post-2015 Global Health Agenda. N Engl J Med 2015 Sep 24;373(13):1189-1192. [doi: 10.1056/nejmp1508807]

8. Greer SL, Méndez CA. Universal Health Coverage: A Political Struggle and Governance Challenge. Am J Public Health 2015 Nov;105(S5):S637-S639. [doi: 10.2105/ajph.2015.302733]

9. Assan A, Takian A, Aikins M, Akbarisari A. Challenges to achieving universal health coverage through community-based health planning and services delivery approach: a qualitative study in Ghana. BMJ Open 2019 Feb 22;9(2):e024845. [doi: 10.1136/bmjopen-2018-024845]

10. Yuan B, Balabanova D, Gao J, Tang S, Guo Y. Strengthening public health services to achieve universal health coverage in China. BMJ 2019 Jun 21;365:12358. [doi: 10.1136/bmj.12358]

11. Binagwaho A, Adhanom Ghebreyesus T. Primary healthcare is cornerstone of universal health coverage. BMJ 2019 Jun 03;365:12391. [doi: 10.1136/bmj.12391]

12. Sanogo NA, Fantaye AW, Yaya S. Universal Health Coverage and Facilitation of Equitable Access to Care in Africa. Front. Public Health 2019 Apr 26;7:102. [doi: 10.3389/fpubh.2019.00102]

13. Limwattananon S, Tangcharoensathien V, Tisayathicom K, Boonyapaisarncharoen T, Prakongsai P. Why has the Universal Coverage Scheme in Thailand achieved a pro-poor public subsidy for health care? BMC Public Health 2012;12(Suppl 1):S6. [doi: 10.1186/1471-2458-12-s1-s6]

14. Tangcharoensathien V, Mills A, Palu T. Accelerating health equity: the key role of universal health coverage in the Sustainable Development Goals. BMC Med 2015 Apr 29;13(1):101. [doi: 10.1186/s12916-015-0342-3] 
15. Tangcharoensathien V, Tisayaticom K, Suphanchaimat R, Vongmongkol V, Viriyathorn S, Limwattananon S. Financial risk protection of Thailand's universal health coverage: results from series of national household surveys between 1996 and 2015. Int J Equity Health 2020 Jan 13;19(1):163. [doi: 10.21203/rs.2.20691/v1]

16. Wagstaff A, Flores G, Hsu J, Smitz M, Chepynoga K, Buisman LR, et al. Progress on catastrophic health spending in 133 countries: a retrospective observational study. The Lancet Global Health 2018 Feb;6(2):e169-e179. [doi: $10.1016 / \mathrm{s} 2214-109 x(17) 30429-1]$

17. Wang M, Li W, Tao Y, Zhao L. Emerging trends and knowledge structure of epilepsy during pregnancy research for 2000-2018: a bibliometric analysis. PeerJ 2019;7:e7115. [doi: 10.7717/peerj.7115]

18. Zhao F, Du F, Shi D, Zhou W, Jiang Y, Ma L. Mapping research trends of retinal vein occlusion from 2009 to 2018: a bibliometric analysis. PeerJ 2019;7:e7603. [doi: 10.7717/peerj.7603]

19. Zou X, Yue WL, Vu HL. Visualization and analysis of mapping knowledge domain of road safety studies. Accident Analysis \& Prevention 2018 Sep;118:131-145. [doi: 10.1016/j.aap.2018.06.010]

20. Wallin JA. Bibliometric Methods: Pitfalls and Possibilities. Basic Clin Pharmacol Toxicol 2005 Nov;97(5):261-275. [doi: 10.1111/j.1742-7843.2005.pto 139.x]

21. 2019 (30 September 2019). GunnMap 2. URL: http://lert.co.nz/map/ [accessed 2019-09-30]

22. Burton C, Elliott A, Cochran A, Love T. Do healthcare services behave as complex systems? Analysis of patterns of attendance and implications for service delivery. BMC Med 2018 Sep 7;16(1):138. [doi: 10.1186/s12916-018-1132-5]

23. Gonani A, Muula A. Point of View: The importance of Leadership towards universal health coverage in Low Income Countries. Mal. Med. J 2015 Apr 24;27(1):34-37. [doi: 10.4314/mmj.v27i1.9]

24. Sumriddetchkajorn K, Shimazaki K, Ono T, Kusaba T, Sato K, Kobayashi N. Universal health coverage and primary care, Thailand. Bull. World Health Organ 2019 Apr 01;97(6):415-422. [doi: 10.2471/blt.18.223693]

25. Sandesh N, Wahrekar S. Choosing the scientific journal for publishing research work: perceptions of medical and dental researchers. Medicine and Pharmacy Reports 2017 Apr 26;90(2):196-202. [doi: 10.15386/cjmed-704]

26. Merigó JM, Núñez A. Influential journals in health research: a bibliometric study. Global Health 2016 Aug 22;12(1):46. [doi: 10.1186/s12992-016-0186-4]

\section{Abbreviations \\ SDGs: sustainable development goals \\ UHC: universal health coverage \\ UN: United Nations \\ WHO: World Health Organization}

Edited by T Sanchez; submitted 24.09.20; peer-reviewed by HA Gorji, S Vatankhah, M Saran; comments to author 29.09.20; revised
version received 15.11.20; accepted 02.12.20; published 11.01.21
Please cite as:
Ghanbari MK, Behzadifar M, Doshmangir L, Martini M, Bakhtiari A, Alikhani M, Bragazzi NL
Mapping Research Trends of Universal Health Coverage From 1990 to 2019: Bibliometric Analysis
JMIR Public Health Surveill 2021;7(1):e24569
URL: $\underline{\text { http://publichealth.jmir.org/2021/1/e24569/ }}$
doi: $\underline{10.2196 / 24569}$
PMID: $\underline{3427687}$

CMahboubeh Khaton Ghanbari, Masoud Behzadifar, Leila Doshmangir, Mariano Martini, Ahad Bakhtiari, Mahtab Alikhani, Nicola Luigi Bragazzi. Originally published in JMIR Public Health and Surveillance (http://publichealth.jmir.org), 11.01.2021. This is an open-access article distributed under the terms of the Creative Commons Attribution License (https://creativecommons.org/licenses/by/4.0/), which permits unrestricted use, distribution, and reproduction in any medium, provided the original work, first published in JMIR Public Health and Surveillance, is properly cited. The complete bibliographic information, a link to the original publication on http://publichealth.jmir.org, as well as this copyright and license information must be included. 